\title{
Senior Management Perceptions of Aspirational Groups: a Study of the UK General Insurance Market
}

Robson, $\mathbf{J}$ and van der Heijden, $\mathrm{H}$.

A version of this paper was accepted for publication in the Journal of Business Research. doi:10.1016/j.jbusres.2015.11.008

\begin{abstract}
This study examines the concept of aspirational groups: a reference group that a firm wishes to associate with. A desire to belong to an aspirational group may provide an important source of strategy formulation. Drawing from insights from consumer marketing on aspirational groups, the study explores the composition and structure of aspirational groups compared to strategic groups in a market setting. Using qualitative data from senior managers in the UK general insurance market, this study arrives at the following findings. First, aspirational groups do not necessarily share the same composition or structure as strategic groups. Second, selection of aspirational firms is driven by attribute association. Third, aspirations can be conflicting and reversed. Fourth, firms do not seek membership of the aspirational group but isolate key attributes they aspire to. These findings contribute to knowledge on strategy formation by highlighting the important role aspirational groups play in understanding competitive market movements.
\end{abstract}

Key Words: Strategic groups. Aspirational groups. Reference groups. Insurance. 


\section{Senior Management Perceptions of Aspirational Groups: a Study of the UK General Insurance Market}

\section{Introduction}

This study explores the concept of aspirational groups in a strategic group setting. Aspirational groups, broadly defined, are reference groups that firms wish to associate themselves with. The concept originated in social psychology and was prompted by the observation that people's behaviour is not only influenced by the groups to which they belong, but also by groups to which they aspire to belong (Bearden and Etzel, 1982; Merton and Rossi, 1968). This study aims to demonstrate that aspirational groups also emerge in a setting where senior managers analyse the firms in their industry sector, and that their presence provides additional insight in strategy formulation and competitive moves in that sector.

Aspirational groups are conceptually similar to strategic groups and share the same unit of analysis. Strategic groups comprise of similar firms in the same group and are typically identified in terms of resource deployment and market scope (Cool and Schendel, 1988; McGee, Thomas, and Pruett, 1995). Firms in these groups are barred from crossing over to other groups depending on mobility barriers (Caves and Porter, 1977). Aspirational groups in this context are defined as groups of firms to which a firm aspires to belong, but is prevented from doing so due to mobility barriers (real or perceived). Aspirational groups may be similar to well-established strategic groups but may also be idiosyncratic and unrelated to such groups. 
Firms are believed to monitor the behaviour of referent firms within their strategic group and adjust their behaviour accordingly (Fiegenbaum and Thomas, 1995; Greve, 1998; Panagiotou, 2007). Firms thus use competitors from their current, existing group as a key reference point for strategy formulation. The contribution of this study is to demonstrate the value of the aspirational group as a second, important reference point for strategy formulation, even if membership of that aspirational group is realistically unattainable.

To illustrate the role of aspirational groups in a strategic setting, this research adopts a cognitive approach where insights are drawn from managers' perceptions of their industry (in line with Lant and Baum, 1995; Peteraf and Shanley, 1997; Porac et al., 1995 and Reger and Huff, 1993). Such an approach is complementary to an econometric approach (see for example, McGee and Thomas, 1986; Fiegenbaum and Thomas, 1990; Thomas and Pollock, 1999; Leask and Parker, 2007; Guedri and McGuire, 2011) where insights are drawn from archival data. The cognitive approach allows researchers to directly access a firm's aspirations, as voiced and articulated by their senior managers, in a way that would be difficult to capture using archival data.

The context in which the research will address these questions is the UK general insurance market. Insurance is a well-recognized context for strategic group studies (see e.g., Fiegenbaum and Thomas, 1990; Fiegenbaum et al, 2001; Ferguson, Deephouse and Ferguson 2000; Esper, Mas and Munillo, 2008; Schimmer and Brauer, 2012). Although it has been common practice in strategic group research to focus on a single industry (see for example, Fiegenbaum and Thomas, 1990), substantial strategic differences may exist at an industry segment level. For example, Ferguson et al., (2000) 
analysed the property/casualty segment of the U.S. insurance industry, and found substantial differences within this industry, along a myriad of strategic dimensions including operating strategies, product offerings, regulatory oversight, scope of operation, and resource deployment. This argument also applies to the UK insurance market and therefore the study confines itself to the general insurance market (i.e. the non-life insurance market which is the UK equivalent of the US property and casualty market).

The study first develops four research questions on how managers within an industry sector look at aspirational groups in their sector. These questions relate to the composition and structure of aspirational groups, how managers perceive them, whether there is a degree of consensus regarding their formation, and to what extent membership of aspirational groups is perceived to be attainable or desirable. The study then addresses these questions using interviews with 25 senior managers in the UK non-life insurance sector, and concludes with a discussion on the contribution of aspirational groups to our understanding of strategy formulation.

\section{Theory and questions}

Strategic group and aspirational group overlap

A question of theoretical and practical interest is the potential overlap in the notion of aspirational groups and strategic groups. The concept of strategic groups dates back to the 1970s when Hunt (1972) first described an intra-industry structure in the US white goods industry. Strategic groups are defined here as a group, or sub-set, of firms within the same industry (Porter, 1979; Carroll, Pandian and Thomas, 1994; Caves and 
Porter,1977), that has formed on the basis of similar combinations of scope and resource commitments (Cool and Schendel, 1988; McGee, Thomas, and Pruett, 1995). The group share a common view of how they are positioned in the market and will make similar decisions in key areas (Porter, 1980). Recent literature has studied performance of firms within and between groups, and has highlighted, amongst others, firm size and intra-group rivalry (Mas-Ruiz and Ruiz-Moreno, 2011), mobility barriers and multimarket competition (Guedri and McGuire, 2011) and retaliation strategies on market entry (Mas-Ruiz et al. 2014).

Aspiration is a notion that appears in the strategy literature; however there is an absence of a consistent terminology and a lack of convergent measures (Hill, Kern and White, 2012). Aspiration is frequently applied in the context of an organizational aspirational and refers to a performance target or goal (see for example, Schimmer and Bauer, 2012; Diecidue and Van de Ven, 2008; Shinkle, 2012) which may be set at an industry average or other basis without reference to an aspirational group. In defining an aspirational group we have returned to its origins in social psychology and consumer marketing to clarify understanding of the term and its application.

Social psychology commonly cites three types of reference groups: membership groups to which the individual already belongs (Bearden and Etzel, 1982; Childers and Rao, 1992; Moschis, 1976); aspirational groups to which the individual aspires to belong to (Bearden and Etzel, 1982; Dholakia and Talukdar, 2004; Lessig and Park, 1978); and dissociative groups that an individual wishes to distance themselves from (Englis and 
Solomon, 1995; White and Dahl, 2007). As with the cognitive strategic groups, the three reference groups are formed in the mental representations of individuals (Escalas and Bettman, 2003) and may change over time when the desired standards are achieved (Chang and Arkin, 2002).

The strategic group aligns most closely with the membership group as the referent firms are within their own group (Fiegenbaum and Thomas, 1990). Observation has however identified that both strategic groups and membership groups fail to fully explain performance and behaviour respectively (Hatten and Hatten, 1987; Barney and Hoskisson, 1990; Johnson, 1993 and Bearden and Etzel, 1982). Within the social psychology and consumer marketing literature, aspirational groups are considered to be a solution to these unexplained results (Bearden and Etzel, 1982).

What is unclear is whether the referent point, the strategic group leader or other members of the strategic group (Fiegenbaum and Thomas 1990; Panagiotou 2007) are also considered aspirational by firms in that group. Could strategic groups be both membership and aspirational groups? Therefore, our first question is: Do aspirational groups overlap with more traditional strategic groupings? Do they have the same composition or even the same level of aggregation?

\section{Composition of aspirational groups}

In social psychology, aspirational groups are those in which a person does not hold membership but wants, or aspires, to become a member (Escalas and Betman, 2003). Aspirational groups can be socially close or distant, real or imaginary, what is important 
is that a positive view is held of that group (Cocanongher and Bruce, 1971; Lessig and Park 1978).

Aspirational groups serve as a positive influence, a level of achievement to which individuals aspire (Childers and Rao, 1992). They can influence information processing, attitude formation and purchase behaviour (Bearden, Netemeyer and Teel, 1989; Dholakia and Talukder, 2004; Escalas and Betman, 2003; Lockwood and Kunda, 1997; Moutinho, 1987). As individuals cannot join the aspirational group simply on the basis of a strong desire to be a member, they attempt to mimic the visible cues or associations of that group so they can be seen by others to be linked, or belong, to that group. For example, when aspirational groups use a brand, consumers may form associations about that brand that they then transfer to themselves thereby creating and projecting an image consistent with the group to which the individual wants to join (Escalas and Bettman, 2003).

Within the strategic group literature, a firm is understood to look to its own strategic group and referent firm therein in order to inform strategic decisions (Fiegenbaum and Thomas, 1995, Panagiotou, 2007). The rationale for this is that firms within a strategic group are similar to each other in terms of key strategic dimensions and the referent firm therefore presents a low risk model to benchmark against (Porter, 1979, Duan and Jin, 2014). Firms are only expected to look further afield and adopt a more risky strategy when they are experiencing performance problems (Levinthal and March, 1981). The social psychology literature would however suggest that firms are potentially aware of 
aspirational groups within their sector and although they may be strategically at a distance to themselves (Porter, 1979) they will have knowledge of their composition. This discussion leads to our second research question: What drives the composition of the aspirational groups in an industry sector, and is this perhaps influenced by attribute associations?

Within-sector consensus of aspirational groups

Within social psychology reference group theory there is an implied hierarchical structure. The members of one group will aspire to belong to another group that is perceived to be more elite, or superior, in some way. Those already in that aspirational group are likely to perceive the other group as inferior and non-aspirational and would wish to distance his or her identity from that group (Amaldoss and Jain, 2008; Bordieu, 1984; Bryson, 1996).

Views on what constitutes an aspirational group do however differ. Englis and Solomon argued that there is 'no single lifestyle that serves as a positive or negative anchor for all consumers. Just as occupied (membership) groups vary widely so do idealized lifestyles aspired to by diverse consumer segments' (Englis and Solomon 1995, p 15). Each consumer segment is therefore likely to have its own aspirational group. However, as consumers learn more about their aspirational group, they make finegrained distinctions, lowering the degree of consensus on the activities of an aspirational group (Englis and Solomon, 1995). Consumers' understanding of the same aspirational groups may therefore, over time, differ within consumer segments. This 
conclusion contrasts strongly to our understanding about the perceptions of strategic group members where firms are locked in to their own strategic group (and disregard other groups) and due to a shared mind they develop a common view of firms within their group. In summary, this leads to the third research question: is there a degree of consensus towards the composition of aspirational groups, or is there a "grass-isgreener" effect where aspirations can be conflicting and even reversed?

\section{Desirability and attainability of aspirational groups}

Within the strategic group literature, mobility barriers prevent firms moving from one group to another (Caves and porter, 1977). Such barriers are also known to exist in the social psychology and marketing literature where although membership of an aspirational group is desired, not all aspirational groups are within reach of the aspiring consumer. In the case of distant groups (Cocanongher and Bruce, 1971) the resources may be impossible to gain to achieve membership. For other, imaginary groups (Lessig and Park, 1978) actual membership is of course impossible. Where an individual is unable to join their aspirational group they will strive to feel like they have achieved their aspiration by taking on the selected associations and behaviours of the aspiration group (Amaldoss and Jain, 2008). The extent to which consumers will adopt the associations is dependent on the degree to which an individual wishes to belong to that group (Escalas and Bettman, 2003) rather than the level of perceived attainability of that group. 
Aspirations are not static. Aspirational groups may change as current aspirations are achieved and membership is gained to the aspirational group. Attention is then transferred to a new aspirational group (Chang and Arkin, 2002). Alternatively, aspirations change over time as the consumer themselves change (Escalas and Bettman, 2003) and a new aspirational group is identified. This leads us to the fourth and final question: Do firms aspire to join their aspirational group or to feel like firms within that group? Is there a realisation that some aspirational groups are "within-reach" whereas others are "completely unattainable" and how does this play a role in the composition and structure of the aspirational group?

\section{Method}

To address the research questions from the previous section, 25 face-to-face in-depth interviews were conducted with insurance executives and industry experts. A challenge for cognitive researchers is how to best identify and measure managerial perceptions (Swan, 1997; Thomas and Pollock, 1999; Huang, 2009). Nath and Gruca (1997) used a direct measure whereby a manager identified firms in their own strategic group. Cheng and Chang (2009) use letters to shareholders in annual reports. Others have used personal construct theory with the aid of the Repertory Grid Technique (Kelly 1955, see e.g. Panagiotou, 2007; Reger and Huff, 1993). In line with these studies, the Repertory Grid was used, and implemented as follows. The names of individual insurance firms were printed on cards and presented to the interviewee three at a time (the triadic method). Interviewees were then asked to identify the "odd-one-out" and give the reason the odd-one-out was identified. In line with Reger and Huff (1993), interviewees 
then rated each insurance firm on the self-supplied constructs using an 11-point scale. The names of the top 50 UK non-life insurance firms by gross premiums were printed on the cards based on Standard and Poor's Synthesys non-life data (CII, 2012). A subset of approximately twelve insurance firms was rated out of maximum 50 (i.e. the top 50 insurers by UK GWP) to avoid fatigue. This procedure produces an $n \times m$ rating grids where $n$ is the number of constructs and $m$ is the number of insurance firms. The rationale for using this technique is that it is easier for senior managers to identify dimensions on which firms are ranked (and thereby implicitly group firms) than to arrive at strategic groups directly (Reger and Huff, 1993).

Aspirational firms were identified by asking each interviewee to name the firms they considered to be aspirational. Interviewees could identify any number of firms (or none), including insurers within and outside their own strategic group or other firms from different industry sectors. Responses were aggregated in order to identify those firms most frequently mentioned and the reasons why. The use of a qualitative approach enabled the researchers to probe deeply into the cognitive maps of respondents and identify the subtle ways in which managers group firms into the different reference groups which would not be possible to capture by means of a survey or econometric approach.

Each interview lasted 45 minutes to one hour, was tape recorded and subsequently transcribed. Nvivo was used to aid data analysis. All data was collected between December 2011 and May 2012.

Interviewees were recruited through the Chartered Insurance Institute's (CII) Underwriting, Claims and Broking Faculties and through local CII institutes. 16 
insurance executives were interviewed, all from the top 30 UK insurance firms as measured by gross premium (CII, 2012). The 9 industry experts represented brokers, industry professional bodies and industry consultants.

All interviewees were highly knowledgeable of the general insurance sector (see Appendix 1). Interviewees had worked within the insurance sector for an average of 27 years, with a minimum of 13 years and a maximum of 40 years. Interviewees held senior positions including Underwriting Director, Head of Claims and Underwriting, Head of Commercial Claims, Managing Director and Chief Executive.

\section{Findings}

Strategic groups and aspirational groups

To examine the possible overlap between strategic groups and aspirational groups in a relatively systematic way, a strategic grouping was first produced with data from the Repertory Grid Technique. The study then put this strategic grouping alongside the aspirational groups that the interviewees identified. To arrive at the strategic groups, the study combined factor analysis with cluster analysis. In the Repertory Grid part of the interviews, interviewees rated 32 firms and identified 249 different variables. A procedure involving successive factor analyses was used to reduce the variables to a more limited set and eliminate overlap ${ }^{1}$. Following this procedure, two factors were

\footnotetext{
${ }^{1}$ The procedure is as follows: first, a factor analysis was conducted on the entire data set and the factor loading matrix was studied (principal components with varimax rotation). Variables were then removed from the data set if they loaded weakly on every identified factor. Variables with high loadings on unique factors were retained. A new factor analysis on the resulting variables was then conducted and the matrix study repeated. This procedure ended with a two-factor solution and seven and ten variables for each respective factor. It is recognized that the procedure employs a subjective interpretation of the strength of factor loadings, and that different solutions can arise under different interpretations.
} 
identified. The first factor included the following variables: 1) market concerns/no market concerns, 2) financial stability/financial problems, 3) no quibble claims/quibble claims, 4) poor quality/good quality, 5) out punching own weight/underperforming, 6) possible merger/stable and 7) hires and fires/stability in people. This factor was labelled Financial Health as a stable, financially sound firm was perceived generally to be of a good quality and to have a no quibble claims policy. The second factor included the variables: 1) composite /personal Insurance only, 2) specialist/broad range, 3) large/small, 4) large accounts/small accounts, 5) all classes of businesses/specialist, 6) large size/small size, 7) international/more UK based, 8) small company/large company, 9) poor product quality/good product quality, and 10) composite/specialist. As the majority of these variables were associated with size, i.e. a large firm was generally a composite insurer, underwriting large accounts and part of an international group, this factor was labelled Size. Factor scores were created for each of the two factors, giving each insurance firm an index for relative financial health and relative size and then a cluster analysis was performed. Good results ${ }^{2}$ were obtained for a four cluster solution (see Table 1).

\footnotetext{
${ }^{2}$ The cluster analysis used K-means clustering. Several cluster solutions were analyzed, and a four-cluster solution had at least two firms in any one cluster, and provided statistically significant differences in the health and size scores. The limitations of cluster analysis are acknowledged, specifically that the choice of method and the number of clusters are subjective, that differences in health and size scores are maximized to produced clusters, and that a cluster analysis will always produce clusters even if they are not present (see also Ketchen \& Shook, 1996). As a result, different choices may lead to different cluster solutions.
} 
Table 1: Cognitive strategic group solution

\begin{tabular}{|l|l|l|}
\hline Group & Description & Firms \\
\hline 1 & $\begin{array}{l}\text { Size: small } \\
\text { Financial } \\
\text { Health: good }\end{array}$ & Chubb, Catlin, Hiscox \\
\hline 2 & $\begin{array}{l}\text { Size: medium } \\
\text { Financial } \\
\text { Health: } \\
\text { medium }\end{array}$ & $\begin{array}{l}\text { Ecclesiastical, MMA, C.N.A., CIS, Domestic \& General, } \\
\text { Esure, Legal and General, Pool Re, SimplyHealth, } \\
\text { Standard Life, Tokio Marine, Travelers, Brit. Ageas, } \\
\text { Liverpool Victoria, QBE, National Farmers Union, BUPA } \\
\text { Chartis, XL, ACE }\end{array}$ \\
\hline 3 & $\begin{array}{l}\text { Size: large } \\
\text { Financial } \\
\text { Health: } \\
\text { medium }\end{array}$ & Aviva, Axa, Zurich, RSA, Allianz, \\
\hline 4 & $\begin{array}{l}\text { Size: small } \\
\text { Financial } \\
\text { Health: Low }\end{array}$ & Direct line, Groupama \\
\hline
\end{tabular}

Strategic groups were also identified on the basis of cluster analysis using archival financial data (company turnover, profitability, etc.) from the year before. A comparison of the two outputs revealed that the results were broadly in-line with each other. Where differences did occur, these could be explained by changes occurring between the different time periods of data collection. For example, Groupama was categorized as 'medium' in terms of financial health in the archival data, but moved to 'poor' health in the repertory grid data as at the time of the interviews Groupama's future was uncertain as its parent company was in financial straits and had announced the disposal of this part of the business (Dunkley, 2012). Differences could also be explained by manager 
perceptions, for example, Direct Line was categorized as 'small' in Table 1, largely as it only operates in the personal insurance market and not the commercial insurance market, whereas analysis of the archival data placed it in the 'medium' sized category due to the size of its personal lines business.

Each expert was asked to identify which firm or firms they considered to be aspirational and the reasons why they were aspirational. Interviewees could identify any firm, including those within and outside their own strategic group and within or outside the top 50 UK insurers. Responses were aggregated to identify the firms most frequently mentioned. Notably, 7 interviewees (4 insurance experts and 3 industry experts) did not consider any insurer to be aspirational. Of the insurers, 3 of the 4 were large (group 3 , Table 1) and the most common reason given by them was that they were already in the top group (based on size) and/or the best within their group so no other insurer was aspirational for them:

No, we think of ourselves as in the top group (Interviewee 7)

I would say that we are probably seen as one of the top of our group, and that's purely based on performance, and actually business accolades that we've had over the years ... things like Commercial Insurer of the Year (Interviewee 9)

In the case of the interviewee from the medium sized insurer, the justification for not seeing any firm as aspirational centred on their own business goal not to follow others but to create their own unique position in the marketplace. When asked if they considered any insurer or group of insurers to be aspirational, they replied:

No. What we aspire to do is do something that is distinctive and different and that will work for us. The reason I say it in those terms is that what I think will 
be the difference in us winning or not is actually creating something that really works for our culture. (Interviewee 11)

This finding does not support the initial assumption made in this study that all firms would have an aspirational firm they looked to aspire to. The majority of interviewees (18) did however identify aspirational insurers and their views are present in Table 2.

Aviva and RSA were seen as aspirational by the medium sized insurers (i.e. those outside the top 10 in size) and industry experts. This was largely based on their scale and underwriting capacity. Allianz and Zurich were also considered aspirational by the medium sized insurers, but for their strong technical underwriting ability and commercial business dominance/capacity to write business respectively. Axa was rated as aspirational by one interviewee for its capacity to write business.

Hiscox, Chubb and Admiral were named as aspirational by both the large and medium sized insurers. Hiscox, for their specialist business and high reputation (due to their strong service levels and knowledgeable staff), particularly in the High Net Worth (HNW) sector. Chubb were also named as aspirational due to their specialist nature and strong technical underwriters. Admiral was considered aspirational due to their unique business model and profitable growth. None of the interviewees identified firms from other industry sectors. 
Table 2 Aspirational Insurance Firms

\begin{tabular}{|l|l|l|}
\hline Insurance Firm & $\begin{array}{l}\text { Frequency (n= } \\
\text { 18) }\end{array}$ & $\begin{array}{l}\text { Reasons given for naming firm as } \\
\text { aspirational }\end{array}$ \\
\hline Hiscox & 6 & $\begin{array}{l}\text { Specialist/ reputation/ excellent service and } \\
\text { knowledgeable }\end{array}$ \\
\hline Aviva & 5 & $\begin{array}{l}\text { Scale/capacity/dominance in SME } \\
\text { market/appetite for business/good brand }\end{array}$ \\
\hline RSA & 5 & $\begin{array}{l}\text { Scale/capacity/technical ability/ financial } \\
\text { strength/shareholder value/good brand }\end{array}$ \\
\hline Chubb & 5 & $\begin{array}{l}\text { Specialist/good reputation for technically } \\
\text { skilled underwriters/ good } \\
\text { service/professional }\end{array}$ \\
\hline Admiral & 5 & $\begin{array}{l}\text { Unique business model. Good } \\
\text { profit/shareholder value/growing quickly }\end{array}$ \\
\hline Zurich & 3 & $\begin{array}{l}\text { Strong technically/ capacity/Underwriting } \\
\text { led/ dominance in business market/ }\end{array}$ \\
\hline Lloyds & 3 & $\begin{array}{l}\text { Good in SME market/capacity to write } \\
\text { business/appetite for growth }\end{array}$ \\
\hline Ecclesiastical & 2 & $\begin{array}{l}\text { Specialist/ do things differently/adventurous } \\
\text { spirit }\end{array}$ \\
\hline
\end{tabular}

Note: In addition, Direct Line, Chartis, Axa, Travelers, QBE, Sabre and Ansvar were each mentioned by one interviewee. 
Strategic groups and aspirational groups

The first research question of the study addresses the issue whether aspirational groups share the same composition and the same level of aggregation as strategic groups. If we compare the composition of the strategic groups (Table 1) with the aspirational group (Table 2) then it can be seen that the aspirational firms identified appear in each of the cognitive strategic groups (Table 1). Hiscox and Chubb from group 1; Ecclesiastical, Chartis, Travelers, QBE from group 2; and Aviva, RSA, Allianz , Zurich and Axa from group 3; and Direct Line from group $4 .^{3}$

Each strategic group therefore contains at least one aspirational firm, the strongest in terms of matching cognitive strategic and aspirational groups is group 3 where all firms in the strategic group received at least one mention as aspirational. Most interviewees divided aspirational firms into two broad categories each with very different associations, i.e. the large and the specialist insurers. The large firms map onto group 3 (Table 1) whereas the specialists are distributed across the different strategic groups depending on their product/market mix.

Two interviewees (interviewee 1 and 3) identified firms within their own group as aspirational. For example, Interviewee 1 compares another large insurer from the same strategic group to themselves in terms of size, distribution and brand and identifies their cost control and service as attributes to aspire to:

\footnotetext{
${ }^{3}$ Note, although Admiral, Sabre and Ansvar were also identified as aspirational companies they do not appear in Table 2. Admiral $\left(\right.$ ranked $49^{\text {th }}$ ) received too few mentions to be included in the final analysis. Ansvar and Sabre are brands within larger groups and therefore their parent companies, Ecclesiastical and SCOR SE, were included in the repertory grid. Lloyds was excluded due to its unique nature when in early pilot interviews respondents experienced difficulties comparing Lloyds with other top 50 general insurance companies.
} 
Obviously they've got a European side to their proposition as well, and their size is very similar to ours. They've got a good global presence, and a good brand. I also think that they're focused on quality, and they have a good balance between cost control and service, and that's what we aspire to.... We aspire to be like them .... although on the claims side I think we're a little bit ahead of them. (Interviewee 1)

Interviewee 3 identifies several aspirational firms, one of which is in the same strategic group as his own firm:

We aim to be a specialist as opposed to a generalist... I guess the ones that stick out as being a bit more specialist in that group are the Hiscox and Markel; they are a bit more specialist and a bit more akin to the way we operate.... Yes, they're generally good. They know what they're doing. They're very professional. That's the sort of group we aspire to be linked with. Hiscox has a cracking reputation, we would like to be seen in the same light as them.... I'd probably add Chubb to that. Chubb, Travelers, who have a very good reputation for the quality of the work that they do (Interviewee 3)

Travelers is the only firm out of the 4 named that shares the same strategic group as that of interviewee 3 . Interviewee 3 is identifying aspirational firms on two criteria: at a sector level where Chubb and Travellers is concerned; and on a specialist level when identifying Hiscox and particularly Markel. Specialism in this context is at sub-sector level and one that is used by the majority of the interviewees to identify aspirational firms. Indeed, aspirational firms were drawn from different sub-groups reflecting the common structural and operational divisions within the sector. For example, the general insurance market is made up of both commercial insurance (for businesses) and personal insurance (for private individuals). These two areas are substantially different, the personal insurance market is largely commoditized compared to the commercial market and different competitors exist in each: 
If I put my commercial lines hat on I'd say probably the likes of Aviva, Axa, Zurich, Allianz in terms of their dominance in commercial lines (Interviewee 9).

There are a lot of specialist firms within the industry who you may aspire to within certain parts of your portfolio, and there are certain specialists who have exceptionally good generic reputations (Interviewee 2)

Other interviewees also identified aspirational firms at a market segment level:

\section{A cracking reputation in HNW (Interviewee 3)}

There is clear evidence that interviewees were not restricting themselves to their own strategic group when identifying aspirational firms, as most firms identified as aspirational were from other strategic groups. In addition, firms were scanning the market and identifying excellence, or market leaders, at different levels: sector, portfolio, product and market segment. Aspirational groups and strategic groups do therefore differ in composition and level of aggregation from strategic groups.

\section{Composition of aspirational groups}

The second question to be addressed was what drives the composition of the aspirational groups?

When identifying the strategic groups, interviewees were found to use 2 factors, financial health and size. When asked to justify their choice of aspirational firms, interviewees also used financial health and size. Financial health in this context was however defined differently to that used in the identification of the strategic groups. In an aspirational context, financial health concerned the profitability of the firm. For example, Admiral, Sabre and Chartis were all identified as aspirational for their financial success 
in terms of profitability, a good return on capital invested, and a good share price. Financial health in the strategic group context centred more on stability.

Size was similarly defined in both a strategic and aspirational context as both included constructs such as: large and composite/small specialist, appetite for business. However in the aspirational context, size was also linked to the capacity to write business, dominance in SME commercial markets and the ability to negotiate deals. Here the focus is more on the benefits that are being leveraged from size rather than size per se.

Size had clear associations, however these differed in nature between the large composites and the smaller specialists (part of the size factor). The larger insurers had the financial capacity to enable them to underwrite large volumes of business in a wide range of business classes and due to their scale and presence they were well known, household names:

Their dominance, their capacity to write business, their appetite (Interviewee 14)

Due to their scale, they have presence, are well known, a household name (Interviewee 6)

By comparison, the smaller insurers were characterised as specialists with competent staff providing them with a good reputation.

The specialists, they know what they are doing. Good reputation for quality - quality underwriting. Good risks. Professional. (Interviewee 3)

...Specialists, who have exceptional, good generic reputations. (Interviewee 2)

... established, reputation within their markets (Interviewee 10) 
This also came through in the interviews with the industry experts who identified the smaller specialists as aspirational:

(They have a) better service and are knowledgeable (Interviewee 24)

We tend to find that insurers which set their stalls out as specialists tend to provide a better service, and their underwriters are more knowledgeable because they're just dealing with that one subject. (Interviewee 25)

And the larger firms as:

....large, mainstream, household names (Interviewee 23)

Although the general consensus amongst interviewees was that the smaller, specialists insurers tended to have quality staff in terms of underwriting expertise, two of the larger insurers, Allianz and RSA were also described in this way. They were unique in that they had both size and underwriting expertise and as a direct result Allianz in particular was identified by both groups, i.e. firms that were smaller and specialist as well as those who were larger and in the same strategic group.

\section{Within-sector consensus of aspirational groups}

The degree of consensus towards the composition of aspirational groups was the third area to be addressed by this study. Are aspirational groups an example of the "grass-isgreener" effect where aspirations can be conflicting and even reversed?

Earlier it was noted that aspirational firms were found in each of the strategic groups identified in Table 1. It was also noted that although some insurers in one strategic group identified firms in their own group as aspirational, the tendency was to identify firms in other strategic groups. On closer analysis of the data, the identification of 
aspirational firms was found to be reversed or reciprocated. In its most simple form, generally the large insurers identified the smaller specialist insurers as aspirational and the smaller specialist insurers identified the larger ones as aspirational.

The larger insurers identified smaller specialist insurers who had strong reputations in their niche markets:

There are a lot of specialist firms within the industry who you may aspire to within certain parts of your portfolio, and there are certain specialists who have exceptionally good generic reputation. (Interviewee 1)

Reputations that relate to the quality of their underwriting, i.e. in terms of the risks they underwrite and the skills and expertise of their underwriters:

They are not that big in the UK .... But they have tremendous reputation for underwriting and cohesion and excellence (Interviewee 2)

I think you're always looking at the QBEs, Brits, some of the small players who are coming to commercial who have very strong service offering, good strong underwriting disciplines (interviewee 12)

In their eyes, small(er) is indeed beautiful.

On the reverse, the smaller insurers saw the large insurers as aspirational:

From a practical point of view they are able to write a lot of business that we have to step away from because it's not part of our appetite or its capacity and those sorts of issues. So in terms of wanting to aspire, yes, l'd like to write all of the business opportunities I get offered, but I can't because we are where we are (Interviewee 9).

Another commented: 
That would be Aviva, RSA and RBSI, who are of course Direct Line, Churchill etc. They have the scale to be able to drive some really strong commercial deals. (Interviewee 16)

The findings from this study differ from the aspirational studies in the consumer behaviour literature as aspirations were not found to be upward or reflect a hierarchical structure. Aspirational firms were both large and small and the aspirations were reversed or reciprocal.

Desirability and attainability of aspirational groups

The final issue to be addressed by this study concerns the question of whether the aspirational group identified is within-reach. Although interviewees identified broad aspirational groups, there was a realism that membership was not attainable, they could not occupy the same space in the market due to the nature and resources the firm had at its disposal. For example, interviewee 10, a smaller firm identified a large firm as aspirational, but beyond reach:

Because of the scale, we will never be an Aviva.. .. the constitution of the firm, owned by a registered charity, we can't raise capital on the stock market in the same way (Interviewee 10)

This viewpoint was also echoed by another smaller insurer, interviewee 14, who aspired to the capacity of the larger insurers, but 'can't because of where we are' .

Firms were also very much aware that the aspirational groups were not without their own problems: As interviewee 16 observed: 
There are some bad things to their size as well ... (Interviewee 16)

Aspirational groups were in this way acting more as positive reference points to compare and contrast their own position and to identify potential ways in which they could improve their own business, rather than as an aspirational group that they wanted to join. The large firms did not aspire to be a specialist insurer, but did aspire to own the associations of the specialist in terms of reputation and quality of underwriting. The smaller specialists wanted the benefits of size but did not necessarily want to become large. This echoes Kemper's observation that individuals may only take selected behaviours and attitudes from an aspiration and then create a new combination or adaptations (Kemper, 1968).

\section{Discussion and Conclusion}

This study addressed a number of unresolved questions in the strategic management literature regarding the role of aspirational groups.

The findings make several contributions to the theoretical literature in strategic and aspirational groups. First, the study identified that aspirational groups do not coincide with the strategic group structure of an industry. There is clear evidence that interviewees were not restricting themselves to their own strategic groups when identifying aspirational firms, but that they were scanning the sector and identifying excellence at different levels: sector, portfolio, product and market segment. Although Fiegenbaum and Thomas (1995) suggested that firms will look to their own strategic group first as a reference point, there was limited support for this in the context of 
aspirational firms. This finding challenges the viewpoint that a firm's strategies are primarily informed by the strategic group in which they operate and suggests that strategizing may be more complex: aspirational firms also provide important clues as to the strategic decisions taken by firms.

Second, although aspirational groups were found to be constructed on a similar basis to strategic groups, managers focused more on the benefits that could be leveraged from financial health and size. In addition, associations were found to exist with the different groupings. This insight suggests that the mental maps managers create of their industry, although shared are quite complex and layered. It is an interesting area of further research to examine to what extent these mental maps are somewhat ephemeral or more persistent over time.

Third, theory suggested that aspirational groups tended to be discrete and hierarchical. This research has found that the perceptions of aspirational groups can be reversed or that there is a mutual recognition of the strengths of different groups. There is a consensus on what constitutes an aspirational group, however, it is generally firms in another strategic group with very different scope and resources that are seen as aspirational. Hence the larger insurers were identifying the smaller specialist insurers as aspirational due to their underwriting quality and reputation; and the smaller more specialist insurers identifying the larger insurers for reasons of financial capacity and the ability to write a broader range of business.

Finally, although firms were found to perceive aspirational firms and groups within their industry, they did not aspire to belong to that group, but wanted to gain the advantages (or associations) of firms within that group. There did exist a realism that the 'grass is 
not always greener' in another group and that it is not always desirable, or indeed feasible, to join the aspirational group.

The concept of aspirations therefore provides more insight into the behaviour of firms within an industry and within a strategic group. In addition, this paper contributes to the debate on how to identify and measure both aspirational and strategic groups. The structure and format of the cognitive strategic groups were compared to those identified from archival data. Similarities were found and key differences could be explained by information emerging from the interviews. These findings illustrate that when using archival data, researchers need to take into account the time decay of the archival data. Events and other changes taking place in the marketplace will alter manager's current perceptions resulting in differences in the groupings. In addition, researchers need to be cognizant of the position and role of the interviewee. In this study insurance experts from the commercial insurance part of the business had differing perceptions from those from the personal insurance side. This adds to the question at what level within an industry should strategic groups be studied? The structure and composition of firms within the industry under question needs to be examined to ensure industry analysis is conducted at an appropriate level. In this context the general insurance market level was too high and a more fine-grained approach would have been appropriate recognizing that firms may focus their strategic efforts in one or relatively few geographic areas, lines of business, or even individual products (Ferguson et al., 2000). 
The findings from this research have implications for managers. Firms are known to monitor the activities of other firms within their strategic group and use this information to inform their activities (Panagiotou, 2007). However, this research has identified that firms look to other groups in terms of their aspirations and this in turn is likely to influence their strategic direction. Benchmarking and other competitor intelligence activities need to take this wider market perspective into account. Insurers can learn from the activities and best practices of insurers located in different strategic groups to their own (the aspirational groups). This would provide a source of competitive advantage going forward, or a potential threat if they themselves neglect to take account of such activities when competitors within their own membership group do so.

This research has several limitations. Data was collected from 25 interviewees in one industry sub-sector. It is recommended that further research continues in the cognitive vein but with a larger sample of insurance executives and industry experts and in different insurance sub-sectors and different industries to explore further how and at what level aspirational firms are identified. In addition, this study has not explicitly investigated the link between aspirational groups and individual firm behaviour, rather aspirational groups have been explored as a potential influence. This research has found that aspirational firms exist and that firms aspire to imitate their success. However, further research is needed to explore the extent to which aspirational firms lead to behaviour assimilation in a strategic group context. 


\section{References}

Amaldoss, W. and Jain, S. (2008). Trading up: A strategic analysis of reference group effects. Marketing Science 27 (5), pp. 932-942

Barney, J.B. and Hoskisson, R.E.(1990). Strategic groups: untested assertions and research position. Managerial and Decision Economics, 11, pp. 187-198

Bearden, W. O., \& Etzel, M. J. (1982). Reference group influence on product and brand purchase decisions. Journal of Consumer Research 9 (9) pp.183-194.

Bearden, W. O., Netemeyer, R. G., \& Teel, J. E. (1989). Measurement of consumer susceptibility to interpersonal influence. Journal of Consumer Research, 15 (4), 473481.

Bourdieu, P. (1984). Distinction: A social critique of the judgment of taste. Harvard University Press, Cambridge, MA.

Bryson, B. (1996). Anything but heavy metal: Symbolic exclusion and musical dislikes. American Sociology Review, 61, pp. 884-899.

Carroll, C., Pandian, J. R. M. and Thomas, H. (1994), Assessing the Height of Mobility Barriers: A Methodology and an Empirical Test in the UK Retail Grocery Industry. British Journal of Management, 5, pp. 1-18

Caves, R. E. and M. E. Porter (1977). From entry barriers to mobility barriers:

Conjectural decisions and contrived deterrence to new competition', Quarterly Journal of Economics, 91, pp. 241-262.

CII (2012). My membership. Cll. London. UK

Chang, I. and Arkin, R.M. (2002). Materialism as an attempt to cope with uncertainty. Psychology and Marketing, 19 (5), pp. 389-406.

Cheng, S.L., Chang, H.C. (2009), Performance implications of cognitive complexity: An empirical study of cognitive strategic groups in semiconductor industry, Journal of Business Research, 62, 1311-1320

Childers, T. L., \& Rao, A. R. (1992). The influence of familial and peer-based reference groups on consumer decisions. Journal of Consumer Research, 19 (9), pp 198-211.

Cocanongher, A.B. and Bruce, G.D. (1971). Socially distant reference groups and consumer aspirations. Journal of Marketing Research, 8, pp. 379-381

Cool, K, and Schendel, D. (1988). Performance differences among strategic group members. Strategic Management Journal, 9, pp. 207-223 
Diecidue, E., \& Van De Ven, J. (2008). Aspiration level, probability of success and failure, and expected utility*. International Economic Review, 49 (2), pp. 683-700. Dholakia, U.M. and Talukdar, D. (2004). How social influence affects consumption trends in emerging markets: an empirical investigation of the consumption convergence hypothesis. Psychology and Marketing, 21 (10), pp. 775-797.

Duan, X., \& Jin, Z. M. (2014). Positioning decisions within strategic groups: The influences of strategic distance, diversification and media visibility. Management Decision, 52 (10), pp. 1858-1887.

Dunkley, J. (2012). Groupama to sell UK business. The Telegraph. 12 $2^{\text {th }}$ Jan 2012. www.telegraph.co.uk/finance/newsbysector/banksandfinance/9011077/Groupama-tosell-UK-business.html

Englis, B. G. and M. R. Solomon (1995). To be and not to be: Lifestyle imagery, reference groups, and the clustering of America, Journal of Advertising, 24 (1), pp. 1328.

Escalas, J., \& Bettman, J. R. (2003). You are what they eat: The influence of reference groups on consumers' connections to brands. Journal of Consumer Psychology, 13 (3), pp. 339-348.

Esper, F.S., Mas, C.V. and Murillo, C. (2008) Competitive analysis with strategic groups: Application to the Spanish insurance sector, 2000-2005. Academia. Revista Latinoamericana de Administración 40, pp 32-53.

Ferguson, T. D, Deephouse, D.L and Ferguson, W.L (2000). Do Strategic Groups differ in reputation? Strategic Management Journal 21, pp. 1195-1214

Fiegenbaum, A. and Thomas, H. (1990). Strategic groups and performance: The U S insurance industry, 1970-84. Strategic Management Journal, 11, pp. 197-215

Fiegenbaum, A. and Thomas, H. (1995). Strategic groups as reference groups: Theory, modelling and empirical examination of industry and competitive strategy. Strategic Management Journal 16, pp. 461-476

Fiegenbaum, A., Thomas, H., \& Tang, M. J. (2001). Linking hypercompetition and strategic group theories: Strategic manoeuvring in the US insurance industry. Managerial and Decision Economics, 22, pp 265-279

Greve, H.R. (1998). Managerial cognition and the mimetic adoption of market positions: what you see is what you do. Strategic Management Journal. 19, pp. 967-988

Guedri, Z., \& McGuire, J. (2011). Multimarket Competition, Mobility Barriers, and Firm Performance. Journal of Management Studies, 48 (4), 857-890. 
Hill, A. D., Kern, D. A., \& White, M. A. (2012). Building understanding in strategy research: The importance of employing consistent terminology and convergent measures. Strategic Organization, 10 (2), pp. 187-200.

Hatten, K. J, and M. L. Hatten (1987). Strategic groups, asymmetrical mobility barriers and contestability. Strategic Management Journal. 8 (4), pp. 329-342.

Huang, K. F. (2009). How do strategic groups handle cognitive complexity to sustain competitive advantage? A commentary essay. Journal of Business Research, 62 (12), 1296-1298.

Hunt, M. S. (1972). Competition in the major home appliance industry, 1960-70, unpublished doctoral dissertation. Harvard University.

Johnson , D . R . ( 1993 ). Testing for intra-industry structure: Do strategic groups exist? Presented at the Annual Meeting of the Academy of Management, Atlanta, GA .

Kelly, G. A. (1955). The Psychology of Personal Constructs, Vols. 1 and 2, Norton, New York

Kemper, T.D. (1968). Reference groups, socialization and achievement. American Sociological Review. 33 (1), pp. 31-45

Ketchen, D.J. and Shook, C.L. (1996). The application of cluster analysis in strategic management research: an analysis and critique, Strategic Management Journal, 17 (6), pp.441-458.

Lant, T. K. and J. A. C. Baum (1995).Cognitive sources of socially constructed competitive groups: Examples from the Manhattan hotel industry. In W.R. Scott and S. Christensen (eds.), The Institutional Construction of Organizations: International and Longitudinal Studies. Sage, Thousand Oaks, CA, pp. 15-38.

Leask, G and Parker, D (2007). Strategic groups, competitive groups and performance within the U.K. pharmaceutical industry: Improving our understanding of the competitive process. Strategic Management Journal, 28, pp. 723-745

Lessig. V. P. and Park, C. W. (1978). Promotional perspectives of reference group influence: Advertising Implications. Journal of Advertising, 7, pp. 41-47.

Levinthal, D. A. and March, J. G. (1981) A model of adaptive organizational search, Journal of Economic Behavior and Organization, 2,(4), pp. 307-33.

Lockwood, P and Kunda, Z. (1997). Superstars and me: Predicting the impact of role models on the self. Journal of Personality Social Psychology, 73, pp. 91-103 
Mas-Ruiz, F. J., Ruiz-Moreno, F., \& De Guevara Martínez, A. L. (2014). Asymmetric rivalry within and between strategic groups. Strategic Management Journal, 35 (3), 419-439.

Mas-Ruiz, F., \& Ruiz-Moreno, F. (2011). Rivalry within strategic groups and consequences for performance: The firm-size effects. Strategic Management Journal, 32 (12), 1286-1308.

Moschis, G.P. (1976). Social comparison and informal group influence. Journal of Marketing Research, 13, pp. 237-244.

McGee, J. and Thomas, H. (1986). Strategic groups: Theory, research and taxonomy. Strategic Management Journal 7, pp. 141-160

McGee, J., Thomas, H. and Pruett, M. (1995), Strategic Groups and the Analysis of Market Structure and Industry Dynamics. British Journal of Management, 6, pp. 257270

Merton, R.K. and Rossi, A.S. (1968). Contributions to the theory of reference group behaviour in Merton R K (ed) Social Theory and Social Structure. New York. The Free Press. $3^{\text {rd }}$ edition. pp. 279-334.

Moutinho, L. (1987). Consumer behavior in tourism. European Journal of Marketing 21 (10), pp. 5-44.

Nath, D. and Gruca, T.S. (1997). Convergence across alternative methods for forming strategic groups. Strategic Management Journal, 18 (9) pp. 745-760

Panagiotou, G (2007). Reference theory: Strategic groups and comparative benchmarking. Management Decision. 45 (10), pp. 1595-1621

Peteraf, M and Shanley, M (1997). Getting to know you: A theory of strategic group identity. Strategic Management Journal, 18, pp. 165-186

Porac, J, .Thomas, H, Wilson, F., Paton, D and Kanfer, A (1995.) Rivalry and the industry model of Scottish knitwear producers. Administrative Science Quarterly. 40, pp. 203-227

Porter, M. E. (1979). The structure within industries and companies' performance, Review of Economics and Statistics, May, pp. 214-227.

Porter, M. E. (1980). Competitive strategy: Techniques for analysing industries and competitors. Free Press. New York

Reger, R.K and Huff, A. S. (1993). Strategic groups: a cognitive perspective. Strategic Management Journal, 14, pp. 103-124 
Schimmer, M., \& Brauer, M. (2012). Firm performance and aspiration levels as determinants of a firm's strategic repositioning within strategic group structures. Strategic Organization, 10 (4), pp. 406-435.

Shinkle, G. A. (2012). Organizational aspirations, reference points, and goals building on the past and aiming for the future. Journal of Management, 38 (1), pp. 415-455.

Swan, J. (1997), Using Cognitive Mapping in Management Research: Decisions about Technical Innovation. British Journal of Management, 8, pp. 183-198

Thomas, H. and Pollock, T. (1999). From I-O Economics' S-C-P paradigm through strategic groups to competence-based competition: reflections on the puzzle of competitive strategy. British Journal of Management. 10, pp. 127-140

White, K. and Dahl, D.W. (2006). To Be or Not Be: The Influence of Dissociative Reference Groups on Consumer Preferences. Journal of Consumer Psychology, 16 (4), pp. 404-13. 


\section{Appendix 1}

Interviewee Profile

\begin{tabular}{|c|c|c|c|}
\hline$\underset{r}{\text { Numbe }}$ & Position & $\begin{array}{c}\text { Industry } \\
\text { experienc } \\
\text { e } \\
\text { (years) }\end{array}$ & Firm Profile (including GWP*) \\
\hline 1 & $\begin{array}{l}\text { Head of } \\
\text { Commercial } \\
\text { Property Claims }\end{array}$ & 25 & $\begin{array}{l}\text { Large, top } 5 \text { insurer. Wide range of } \\
\text { commercial and personal products. } \\
\text { European owned. }\end{array}$ \\
\hline 2 & $\begin{array}{l}\text { Director of } \\
\text { Commercial } \\
\text { Underwriting }\end{array}$ & 30 & $\begin{array}{l}\text { Large, top } 5 \text { insurer. Wide range of } \\
\text { commercial and personal products, } \\
\text { stronger in personal market. UK owned. }\end{array}$ \\
\hline 3 & $\begin{array}{l}\text { Underwriting } \\
\text { Director }\end{array}$ & 40 & $\begin{array}{l}\text { Medium sized, top } 30 \text { insurer. Commercial } \\
\text { and Personal. Developed from niche } \\
\text { business. UK owned. NPO status. }\end{array}$ \\
\hline 4 & $\begin{array}{l}\text { Underwriting } \\
\text { Director }\end{array}$ & 25 & $\begin{array}{l}\text { Medium sized, top } 15 \text { insurer. Mainly } \\
\text { personal but also commercial. European } \\
\text { owned. }\end{array}$ \\
\hline 5 & $\begin{array}{l}\text { Head of UK } \\
\text { Claims }\end{array}$ & 29 & $\begin{array}{l}\text { Medium sized, top } 25 \text { insurer. Mainly } \\
\text { commercial but also personal products. }\end{array}$ \\
\hline 6 & $\begin{array}{l}\text { Commercial } \\
\text { Underwriting } \\
\text { Manager }\end{array}$ & 27 & $\begin{array}{l}\text { Medium sized, top } 20 \text { insurer. Commercial } \\
\text { and Personal. Developed from niche } \\
\text { business. NPO status. }\end{array}$ \\
\hline 7 & $\begin{array}{l}\text { Underwriting } \\
\text { Director }\end{array}$ & 33 & $\begin{array}{l}\text { Large, top } 10 \text { insurer. Wide range of } \\
\text { commercial and personal products. } \\
\text { Retains some specialist markets. } \\
\text { European owned. }\end{array}$ \\
\hline 8 & $\begin{array}{l}\text { Head of Claims } \\
\text { and Underwriting }\end{array}$ & 31 & $\begin{array}{l}\text { Large, top } 5 \text { insurer. Wide range of } \\
\text { commercial and personal products. } \\
\text { European owned. }\end{array}$ \\
\hline 9 & Branch Manager & 33 & $\begin{array}{l}\text { Large, top } 10 \text { insurer. Wide range of } \\
\text { commercial and personal. European } \\
\text { owned. }\end{array}$ \\
\hline 10 & $\begin{array}{l}\text { Head of Risk } \\
\text { Management }\end{array}$ & 34 & $\begin{array}{l}\text { Medium sized, top } 30 \text { insurer. Commercial } \\
\text { and Personal. Developed from niche } \\
\text { business. UK owned. NPO status. }\end{array}$ \\
\hline 11 & $\begin{array}{l}\text { Head of } \\
\text { Commercial } \\
\text { Claims }\end{array}$ & 17 & $\begin{array}{l}\text { Large, top } 10 \text { insurer. Wide range of } \\
\text { commercial and personal. UK owned. }\end{array}$ \\
\hline 12 & $\begin{array}{l}\text { Head of } \\
\text { Combined } \\
\text { Europe } \\
\text { Commercial }\end{array}$ & 20 & $\begin{array}{l}\text { Large, top } 10 \text { insurer. Wide range of } \\
\text { commercial and personal. US owned. }\end{array}$ \\
\hline 13 & $\begin{array}{l}\text { Marketing Insight } \\
\text { and }\end{array}$ & 25 & $\begin{array}{l}\text { Large, top } 10 \text { insurer. Wide range of } \\
\text { commercial and personal products. }\end{array}$ \\
\hline
\end{tabular}




\begin{tabular}{|c|l|c|l|} 
& $\begin{array}{l}\text { Planning } \\
\text { Manager }\end{array}$ & $\begin{array}{l}\text { Retains some specialist markets. } \\
\text { European owned. }\end{array}$ \\
\hline 14 & $\begin{array}{l}\text { Mammercial } \\
\text { Manager }\end{array}$ & 39 & $\begin{array}{l}\text { Medium sized insurer, top 15. Mainly } \\
\text { personal but expanding into commercial. } \\
\text { UK owned. }\end{array}$ \\
\hline 16 & $\begin{array}{l}\text { Underwriting } \\
\text { Director }\end{array}$ & 23 & $\begin{array}{l}\text { Large, top 10 insurer. Wide range of } \\
\text { commercial and personal. European } \\
\text { owned. }\end{array}$ \\
\hline 17 & $\begin{array}{l}\text { Head of Gl } \\
\text { Operations }\end{array}$ & 35 & $\begin{array}{l}\text { Medium sized, top 25 insurer. Mainly } \\
\text { personal but also commercial. UK owned. } \\
\text { NPO status. }\end{array}$ \\
\hline 18 & $\begin{array}{l}\text { Executive } \\
\text { Director }\end{array}$ & 15 & $\begin{array}{l}\text { Small commercial and personal insurance } \\
\text { broker. Regionally based. }\end{array}$ \\
\hline 19 & Owner & 32 & $\begin{array}{l}\text { Industry Professional body } \\
\text { Consultancy firm specialising in the UK } \\
\text { general insurance and related sector. }\end{array}$ \\
\hline 20 & Chief Executive & 28 & $\begin{array}{l}\text { Large, mainly commercial but also } \\
\text { personal insurance broker. National } \\
\text { distribution. }\end{array}$ \\
\hline 21 & $\begin{array}{l}\text { Head of } \\
\text { Commercial }\end{array}$ & 13 & $\begin{array}{l}\text { Large, mainly commercial but also } \\
\text { personal insurance broker. National } \\
\text { distribution. }\end{array}$ \\
\hline 22 & $\begin{array}{l}\text { Managing } \\
\text { Director }\end{array}$ & 23 & $\begin{array}{l}\text { Large, commercial and personal insurance } \\
\text { broker. National distribution. }\end{array}$ \\
\hline 23 & $\begin{array}{l}\text { Commercial } \\
\text { Manager }\end{array}$ & 15 & $\begin{array}{l}\text { Small commercial and personal insurance } \\
\text { broker. Regionally based }\end{array}$ \\
\hline 24 & $\begin{array}{l}\text { Commercial } \\
\text { Manager }\end{array}$ & 30 & $\begin{array}{l}\text { Medium sized commercial and personal } \\
\text { insurance broker. Regionally based }\end{array}$ \\
\hline Executive & 19 & \begin{tabular}{l} 
Industry Professional body \\
\hline
\end{tabular} \\
\hline
\end{tabular}

* insurer size is ranked by gross written premium using Standard and Poor's Synthesys non-life data (CII, 2012). 